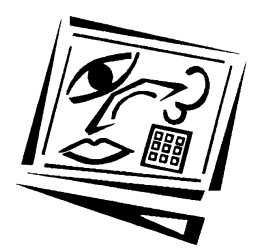

\title{
Using desktop video to enhance music instruction
}

\begin{abstract}
Alan J. Anderson and Allan Ellis
Southern Cross University

In the last few years, many of the early technical limitations of desktop digital video technology have been overcome thus paving the way for its application in various fields of education and training. Fields in which manual skills are passed on by physical demonstration probably stand to gain the most. In the visual and performing arts, for example, there is reliance upon master instructors and their ability to demonstrate refined manual techniques at close quarters. Such action is fluid and audiovisual in nature, therefore attempts to capture it in still images, such as found in conventional music method books, are often of limited success. In contrast, digital video can capture actions in full motion and in a format that can be replayed, edited, and delivered online using a desktop computer. This paper examines how the current generation of desktop video technologies can improve the delivery of music instruction in the short term and in due course may facilitate a paradigm shift in music education.
\end{abstract}

\section{What is the traditional approach to teaching a student to play a musical instrument?}

Madsen (1969, p.6) notes that "musicians basically use traditional approaches that have been passed down through the ages." Even in some of the best institutions, he claims, "the tacit assumption prevails that the best, if not the only, way to study music is to apprentice with a master" (p.7). Though he concedes "there are inherent advantages to apprenticeship" (p.6), Madsen argues that apprenticeship systems are out of step with demands of modern music education since they leave little room for speed and efficiency. Clearly, not much has changed since 1969, as more recent research by Persson (1996) and Hays (1998) reveals that the master-apprentice or mentor approach remains entrenched in music education and the psyche of music educators. Certainly most music schools and individual private teachers still advocate traditional face to face individual tuition as a matter of course. Usually, students have one half-hour face to face lesson per week. These lessons are often supplemented by paper based print, with some photos and audiotapes. 


\section{What is involved in learning to play a musical instrument?}

Interestingly, research has shown that regardless of variables like degree of access to quality tutors and learning environments, individual practice is the primary means by which music students learn instrumental performance skills (Hoffer, 1991; Scott, 1994; Brodsky, 1995). Powell (1984), Geake (1987) and St George (1990) note that although it is part of a teacher's responsibility to guide the student in how to practice, ultimately students must apply themselves. St George (1990) argues that teachers should help their students to understand that learning is a 'teach thyself' situation, because students who are able to teach themselves will make the best use of the information.

\section{Self directed learning or shortcut?}

'Easy play' method books rightly promote the benefits of self directed learning. However, some of these books tend to understate the relevance of music theory, reading skills, and guidance from an experienced teacher. For example, in the foreword of "Pointer System for Guitar", Van Auken (1964, p. 1) states, "the step-by-step features of this method enable a student to sing and play his first song in a matter of minutes - even without the help of a teacher." Van Auken features one-dimensional diagrams that show where the fingers should be positioned on the strings above the guitar fretboard in order to play various chords (Figure 1).

The chord symbols, for example, 'C' or 'G7' are written above the melody and lyrics of old folk songs that the student is expected to sing while strumming the accompanying chords. Chord diagrams are featured in numerous guitar tutor books and on sheet music, and they are quite accepted as a useful aid to learning (Turner and White, 1979; Bay, 1980). However, these diagrams tell only half the story and without more in depth study the student may be left with a very limited understanding of their instrument and the music they aspire to play.

Weigert (1997, p. 45) asserts that "sometimes inexperienced musicians don't know what to practice and thus open method books that don't relate to the skills they really need to develop". Even the best intentioned player, Weigert adds, may exclusively practice one dimensional scales and rudiments from exercises in books assuming that one can simply "do this, this and this and get a certain quantifiable result" (1997, p. 43). However, he concedes the best way for students to obtain the musical confidence they need is to listen to, analyse, and systematically play along with the best of recorded music. Some tutor books go some way to providing students with that option because they come with an accompanying audio cassette or audio CD. 


\section{A New Chord - The D7 Chord}

D7

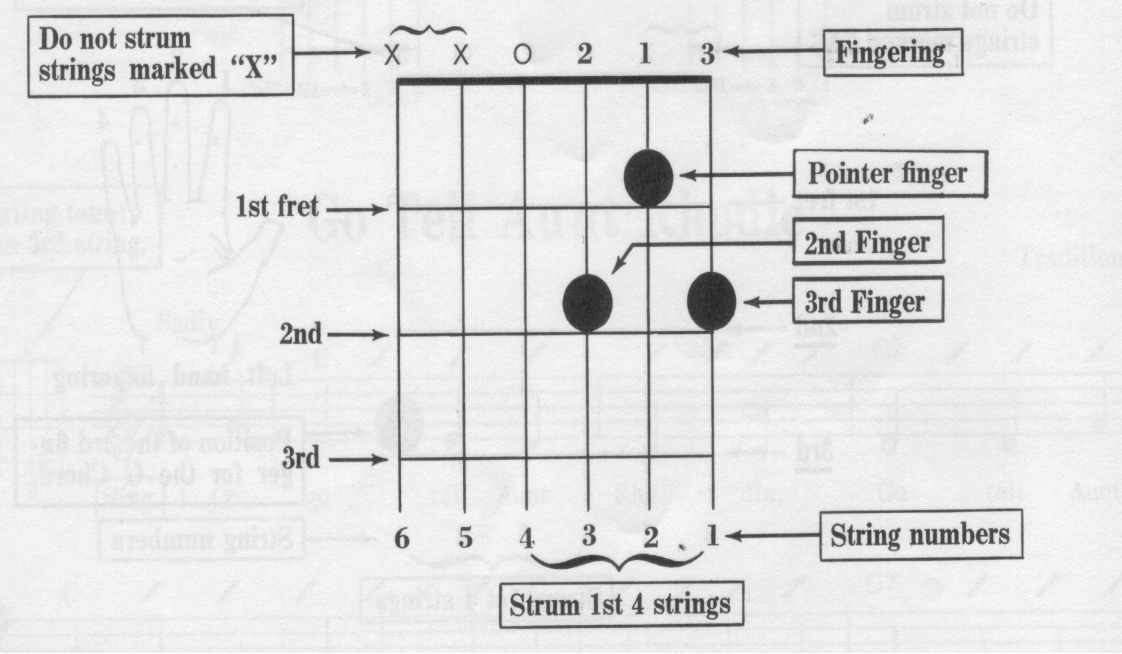

Figure 1: A D7 Chord Diagram from Van Auken (1964, p. 1)

\section{Comprehensive music tutor books with audio cassettes and CDs}

In contrast to the 'easy play' style of book discussed earlier, comprehensive tutor books such as the "Mel Bay's Guitar Method" series, are specifically designed for teacher and student to work through together (Bay, 1980). Emphasis is placed on the development of music literacy as well as instrumental performance skills. Furthermore, audio cassettes and audio CDs of selected exercises in each book are made available for purchase. These provide the student with an additional point of reference for inter-lesson practice sessions. Of course, listening to tapes as well as reading the music notation helps to improve aural perception (Weigert, 1997; Fitzgerald, 1999). Finally, these books also include diagrams or photos to demonstrate the correct body posture and positioning of hands and fingers for performing various techniques. These visual aids are helpful because it is important to learn correct instrumental technique. Good technique facilitates good sound production and helps to avert repetitive strain injuries and the like (Branfonbrener, 1995; Brodsky, 1995; Wenig, 1994; Newman, 1994). Because they are one dimensional, however, 
pictures are not likely to be as effective as repeated demonstrations by ones teacher at close quarters. Video, on the other hand, if filmed to show multiple perspectives of particular techniques or body posture, is closer to the ideal medium.

\section{Conventional VHS video}

Since the 1970s instructional VHS music videos (designed to play on a standard television screen) have become a popular means for music students to study the techniques used by other musicians who inspire them. Commonly these videos focus on unique techniques that a particular master musician has become renown for (DCI Music Video Productions, 1983). Such features add to the popularity of instructional music videos and make them a relevant student resource. However, sometimes it seems that video producers and directors become preoccupied with hastily capturing the 'best of' techniques from the performer's bag of tricks at the expense of the instructional quality of the video. An example of this would be the commercial video tape "Steve Gadd Up Close" (DCI Music Video Productions). The potential of that video as a medium for education seems to be lost due to the lack of instructional design and forward planning on the part of the video production team. For example, the interviewer, reading from a note pad on occasion, seems to have planned his questions prior to filming. However, when Gadd responds to questions about body posture (verbally and by demonstration), the action is shot primarily from one angle.

Furthermore, a number of Gadd's comments, for example, "I don't know exactly how I do it ... was my body moving then?" indicate he may have provided a firmer response given some time for forethought on the matter. Ironically, the musician being filmed may know better, based on years of teaching experience, the best camera angles applicable to demonstrating her/his craft, but the producer is customarily in control of these things. To that end, music teachers who learn to use desktop video may well come to make more useful videos than those commercially produced. The advantages and processes involved in this will be discussed in the section on integrating desktop video into music education.

\section{Developments in desktop video}

Surely the most significant of technical developments in desktop computers from the teacher and music students' point of view have been those which have helped to make multimedia software and devices more affordable and user friendly. Certainly, this has been a priority for the product designers and manufacturers who have driven these innovations (Kaufman, 1999; Healy, 2000). Evidence of their success can be seen in 
plug ' $\mathrm{n}$ ' play technology which Healy (2000, p. 80) notes "has advanced pretty much to the stage where saying that something is easy to install is almost redundant" and where operating WebCams is "child's play."

Perhaps with the exception of some of the latest IEEE 1394 standard (also known as FireWire and iLink) equipped models, most computer digital video cameras (commonly referred to as WebCams) are not designed to produce professional quality images. Nevertheless, these devices do provide a cheap way to create short digital movie files or snap shot files which can then be integrated into computer based multimedia projects (Healy, 2000). Furthermore, using a standard WebCam and a microphone, users can record a digital video message and send it as an email attachment (Wales, 2000).

Digitising video reduces images to mathematical algorithms that computers can read (Salvador, 1994). This allows video to be stored onto a computer's hard disk, a CD-ROM, DVD or a floppy disk. In the early 90s, to run digital video on a desktop computer, additional software or boards, such as MPEG player software or card was required (Salvador, 1994). Since the late 1990s, however, products like Apple's QuickTime allow users to integrate video into their multimedia presentations without add ons as it is all built into the software. In spite of such advances, however, compared to analog video, digital video can still be prone to glitches in terms of providing consistent clarity of image. For instance, a jerkiness and out of sync quality is common when frame rates are slower than around 24 frames per second (fps). Of course, people are accustomed to the smooth and reliable quality of television and analogue video. Therefore, it stands to reason that some people are surprised at the lesser quality of digital video and may even see it as a regressive step in technology.

Interestingly, Salvador (1994) notes that movies play at 24 frames per second (fps), TV (PAL) runs at $30 \mathrm{fps}$, and the specifications quoted on recent USB and IEE 1394 interface, desktop digital video cameras indicate these devices are well capable of such frame rates (Logitech, 1998; ADS Technologies, 2000). This raises the question: why is jerkiness and out of sync quality still a problem? Documentation on the Kodak DVC325 notes video capture up to $640 \times 480$ pixels resolution or up to $30 \mathrm{fps}$ performance (Eastman Kodak, 1999). This level of performance, Kodak note, is facilitated by its USB interface which allows up to ten times faster throughput than serial interfaces. ADS technologies claim that their PYRO 1394 WebCam, aided by its IEEE 1394 interface, can transfer data twenty times faster than USB thus allowing $30 \mathrm{fps}$ at $640 \times 480$ pixels resolution.

These levels of performance may be achievable under optimum conditions, but there are a number of variables that can affect 
performance, some hardware related and some software related. Factors such as the power and speed of the computer's CPU, the operating system, amount of RAM and bandwidth come into play. So to be precise, these cameras can capture up to $30 \mathrm{fps}$ but the final quality is subject to image size, resolution and the user's system. Even with reasonably powerful computers, for example, an iMac G3 DV SE / $500 \mathrm{MHz}$ or a G4 / 400MHz, to achieve the best frame rate some compromise in respect to image size, resolution and file size is necessary. For example, in the case of the Logitech QuickCam VC, keeping the video resolution down to around 160 pixels x 120 pixels rather than 320 pixels x 240 pixels. Healy (2000, p. 80) notes that "the standard size for video is 176x144 pixels", therefore $320 \times 240$ is "a rather high end setting." Put simply, if the user's system is a bit low on power, bandwidth and so on, it would be necessary to reduce the on screen viewed area to as small as $4 \times 3$ centimetres in order to produce a smooth, movie quality video.

A more powerful system on the other hand could produce and replay a comparable quality video of similar length at an on screen viewed area of around $6 \mathrm{~cm} \times 5 \mathrm{~cm}$ or even larger. By opening a QuickMovie file with QuickTime Movie player it is possible to expand images to around $20 \times 13$ centimetres frame size with little effect on sync. However, as the view is expanded further to full screen size, the resolution, fluidity and sync drops off accordingly; but not so much as to be unworkable for certain aspects of music instruction. Such compromise is essential when sending self contained video files as email attachments. Perkins (cited by Wales, 2000) says the best strategy for sending video over slow connections is to keep the picture size low at 240 by 180 pixels. Probably, by the time high speed broadband networks are as ubiquitous as personal computers, such limitations will all but disappear. But until then, those with a mind to distribute video files this way for distance education purposes must keep mindful of the lowest common denominator in terms of the client's computer and connection speed.

\section{Integrating desktop video into music education}

Undoubtedly most music teachers could recall students whom on arrival for a rehearsal or private lesson have announced "I wasn't able to learn my piece because by the time I got home I had forgotten that technique you showed me for playing it." Relatively low cost desktop computer based digital video technology now makes it feasible for music teachers to produce video files of themselves demonstrating particular techniques. Once compressed, these files can be copied to disk and given to the student to take home and thereby facilitate their inter-lesson practice. A small file of, for example, a close up view of the technique for playing an arpeggio, scale or snare drum rudiment can be compressed to fit on a 1.4 
MB floppy disk. While using Super disk drives, CD writers or emerging DVD writers enables the user to record and store even longer movies, for example, several pieces performed from start to finish. With access to a suitable personal computer and software, students can replay such files as often as they choose. While the facility to scroll through the video means that the finer details of techniques which are sometimes too difficult to observe with the naked eye or in a snap shot can be viewed frame by frame. Of course, typical VHS format instructional music videos can be replayed as required too but they require rewinding and repositioning which can become tedious as one waits for the mechanical processes to be completed. The virtual controls of a QuickTime digital video player are shown below (Figure 2). Like the controls of a traditional VHS recorder, the large arrow is for 'play' and the smaller buttons activate the pause function, control volume and so on.

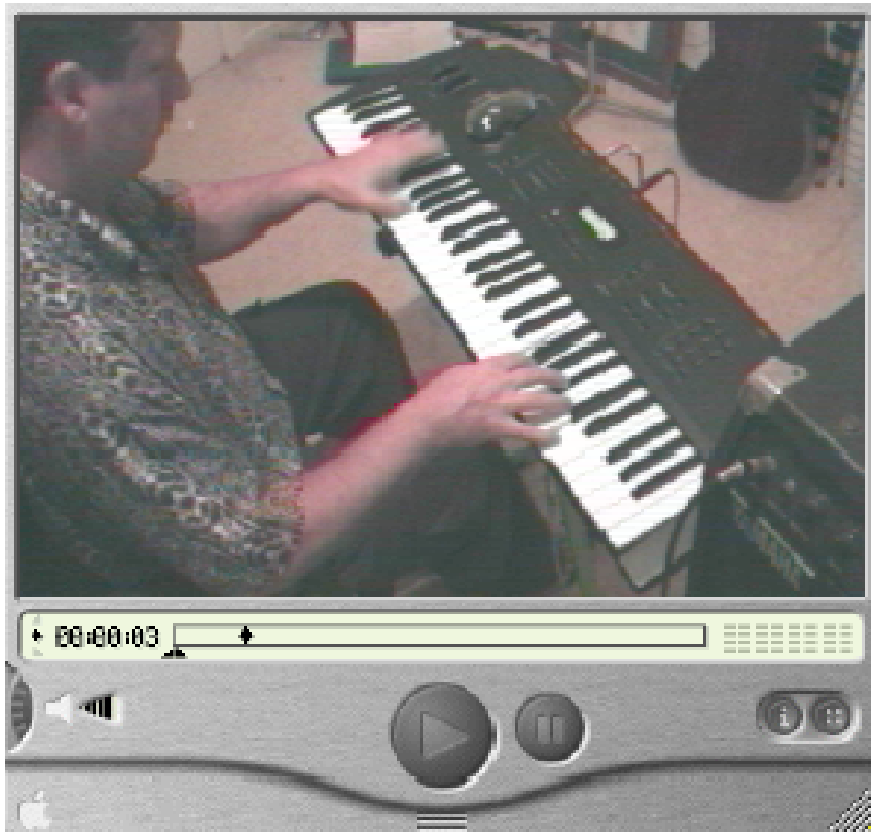

Figure 2: Virtual controls of a QuickTime digital video player

Digital video files can also be used in conjunction with other multimedia applications (such as Microsoft PowerPoint). Consequently, the best features of the traditional tutor book can be expanded on in the production of read only or read write texts. For instance, music notation and/or text files inserted beside movie files to explain the finer points of an instrumental performance technique (Figure 3). 

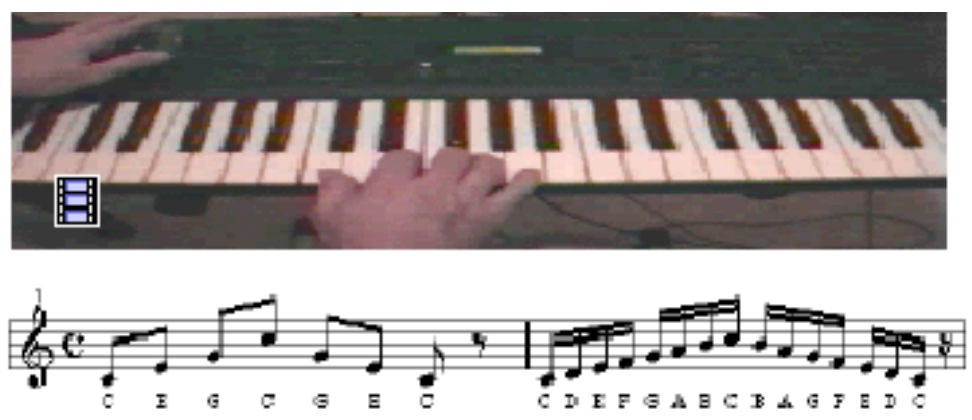

Figure 3: Digital video file integrated into multimedia presentation showing notation for C major Arpeggio and C Major Scale.

Such features should satisfy the requirements of teachers who prefer to work primarily from music notation as well as those who prefer just words, diagrams and demonstrations to get their point across. Of course, it is also possible to insert voice over audio files separately. Because audio requires less file space than video, this may be helpful if one is aiming to keep overall sizes to a minimum.

\section{Current investigations}

As the first stage of a larger study to determine the practicalities and pedagogical issues of teaching musical instruments online, the first author has conducted a series of pilot studies. Five professional music teachers and ten students ranging from rank beginner through to third year undergraduate music students participated in the study. Each teacher taught several students in succession by video conference. Individual teachers and students were located in separate rooms of the same building and they communicated with each other via video conference terminals (iMac G3 computers fitted with Pyro WebCams and VideoLink Pro video conference software) set up in each room. These computers were connected by an Ethernet crossover cable or in some cases by Apple's Airport wireless network occasionally swapping back to Ethernet crossover connection to compare performance. The Airport network maximum data rate was $11 \mathrm{Mbps}$ compared to $100 \mathrm{Mbps}$ for the Ethernet 100 Base-T network connected by a category 5 crossover cable. Interestingly, the video conferencing performance remained much the same whether connected by Airport or Ethernet. This is probably due to the fact that "desktop video conferencing systems are [typically] designed to work with lower bandwidth connections" (Shepard, 2001). Consequently, they must do a lot of compression and, irrespective of the connection speed, the video conference software has limits to how fast it 
can translate analog voice data into digital data (Fitzgerald \& Dennis, 1999). Shepard (2001) concludes, "one of the biggest things on the horizon is the development of codecs that don't use compression. Of course, that means really high bandwidth and really good Quality of Service (QoS)."

In the pilot study, instruments taught by video conference consisted of acoustic guitar, electric guitar, electric bass, acoustic double bass, drum kit, snare drum and tuned percussion, and flute. These lessons, and postlesson interviews, were recorded on videotape and later, a comparative analysis of video footage of each lesson and interview was conducted. Given the exploratory nature of this study, and a lack of relevant qualitative - much less quantitative - data to use as a point of reference, it was considered appropriate to adopt an action research methodology. Central to the rationale for using this methodology was the researcher's desire to avoid premature commitment to a particular research question or to confirming or refuting a particular hypothesis at the expense of exploring tangents that may prove significant (Neuman,1997).

In practice, this meant that if a particular camera angle, for instance, was found to be of no use to capture a technique like fingers picking the strings of a guitar, then it was not considered necessary to replicate that procedure to 'prove' its futility. The sequence of action was as follows: identify problem; form initial plan, act, monitor, evaluate, revise plan, act, monitor, evaluate, revise plan and so on, ideally leading to improved practice after each cycle. Each group of two or three video conference mediated lessons constituted an action learning cycle within the first broader cycle of a series of three planned to continue into 2002. As the pilot study progressed, the results of the first group of lessons informed the second; the second informed the third and so on. For example, initially, teachers were asked to teach as they usually do and not concern themselves with any special lesson preparation relevant to the video conference medium. In successive lessons, however, teachers and students were asked to try procedures that were generated during or following the analysis of the previous lessons.

As anticipated, teachers had no sooner commenced their lessons when they encountered challenges such as not being able to spontaneously write a musical exercise on a piece of paper and physically hand it to the student. This problem was easily solved, by scanning the document and sending it to the other computer by file exchange or email attachment. The recipient (a student in most cases) would simply re-position their video conference window making room for a second window displaying the scanned image of the music. Several students were not satisfied with the view so they simply printed a copy at their end. As several participants remarked, larger monitor screens would help to alleviate this problem. 
Another obstacle, particularly with respect to string instruments such as guitar and bass, was that students could not always see their teacher's finger movements precisely if displayed at smaller frame sizes. As mentioned earlier, it is sometimes necessary to select smaller frame sizes in order to achieve sufficiently fluid video motion. Figure 4 shows the VideoLink Pro conferencing window displayed on the screen of an iMac computer. Note the buttons on the left side of the window above and below the small 'local' view of the user (male teacher). To the right of the 'local' user camera view is the remote camera view of the student (female) at the other end terminal. The square buttons above the local view allow the user to select a small, medium or large view of the remote user.

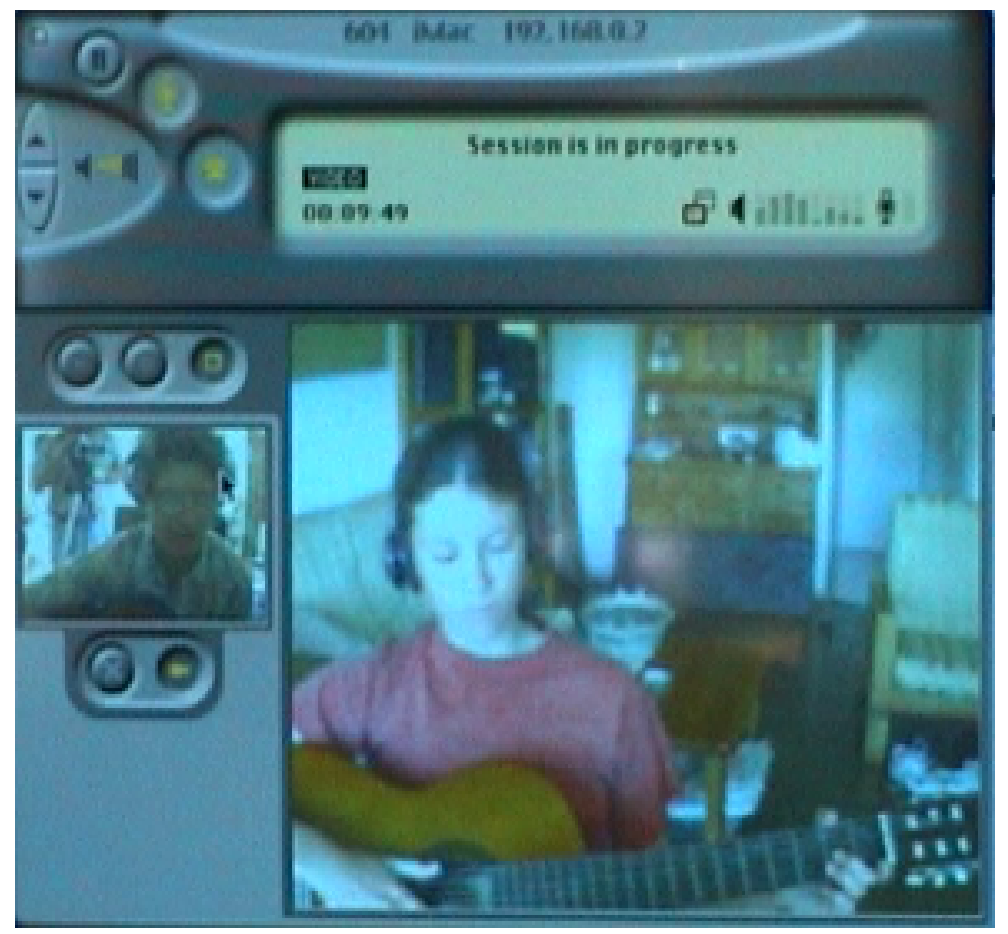

Figure 4: A screen grab of a desktop video conferencing session in progress (teacher left, student right)

Interestingly, unlike their beginner level students, the two guitar teachers who participated said that not being able to see their students' finger positions clearly was not particularly challenging.

Researcher: "Can you see her fingers clearly on the fretboard? Guitar teacher: "Not very clear ... but I've got my ears!" 
What this teacher meant was that his experience and expertise in recognising the sound of a chord or melody simply by hearing it tells him whether the student's fingers are correctly positioned. Indeed, this level of aural perception is essential for professional musicians and music teachers. Furthermore, it is a factor that has significant implications in terms of determining what constitutes workable quality audio and video. Just as one faces a trade off regarding size of video frame versus sync or fluidity, the same applies with respect to the quality of audio versus video. Consequently, music educators or institutions planning to deliver music teaching by desktop video conferencing should take this into consideration. Clearly, any software and hardware acquired for that purpose must be designed, like VideoLink Pro software, to allow teachers and students to adjust audio and video settings to suit their purpose at a given time.

The pilot study confirmed that pre-recorded digital video files (e.g. QuickTime ) provide a workable solution to the challenge of providing students with a detailed view of instrumental performance techniques. For instance, the teacher can simply prepare a still image or short replayable video file showing the finger positions the student needs to learn/use in a particular lesson. However, another option for synchronous video conferencing, is to replace the WebCam on the teacher's desktop computer with a more expensive digital video camera fitted with a zoom and wide angle lens. This would allow teachers to zoom the camera in on her or his own hands and fingers on the fretboard or keyboard as the case maybe. According to Maki (2001) this is in fact superior to having students in a conventional face to face situation trying to look on from a distance of several meters. University of Oulu music teachers have been using this strategy successfully while teaching students in remote Lapland classrooms by large scale ISDN video conferencing systems (Maki, 2001). A word of caution to buyers however: That strategy failed in the pilot study discussed here. For reasons unknown at this stage, the Sony TRV330E Digital 8 camera used would interface successfully with the iMac computer and various video editing programs including "Video Impression" (which came with the Pyro IEEE1394 WebCam) but it would not interface with the VideoLink Pro video conferencing software.

The most challenging problem encountered in the pilot study was that of audio delay induced by the compression algorithms of the codecs. At present, even large scale video conference systems connected by high speed broadband networks are hampered by audio delay. Like the University of Oulu, Finland, the University of Oklahoma, USA, uses a large scale video conference system to teach music between campuses. As noted by Brian Shepard, Coordinator of Music Technology Programs University of Oklahoma School of Music, "when you combine that with 
the travel time (speed of light and network delays) you often encounter one way delay times in the range of 120-150 milliseconds. It's pretty good, but still not good enough for duet playing" (Shepard, 2001). This is a significant problem for instrumental teaching online because teachers typically play along to accompany their students, especially in cases where the student is learning to play a 'call and response' blues or jazz blues style improvised solo.

Providing a simple non-improvisational accompaniment is less problematic because, as this pilot study determined, it is possible for the teacher to pre-record the accompaniment. The accompaniment piece can be stored on floppy disk, CD-ROM or a server for the student to download before or during a lesson by video conference. Subsequently, during a lesson by video conference, the teacher can listen to the student play along with the pre-recorded piece. This was done quite successfully during the pilot study, however, some delay, echo and audio feedback was encountered as the audio signal of the digital video file being re-played was picked up by the computer's in built microphone and sent to the remote computer (video conference terminal) via the video conference software. Interestingly, the computers used had no trouble in maintaining a stable video conference connection while QuickTime Videos were played at one end. Similarly, file sharing while video conferencing did not cause the link to become unstable or result in a dramatic drop in performance. The most obvious troughs in performance occurred when either musician played fast, loud and complex musical passages. These drops in performance were particularly noticeable if both players attempted to play such passages at the same time. Apparently this was a case of simply too much data too fast for the computers to translate, transmit and receive without momentarily faltering. Teachers and students soon got the idea and simply waited their turn.

The series of pilot studies reported here are still in progress. Therefore, it would not be appropriate to generalise prematurely about the quality of the teaching and learning that has taken place. Over the next twelve months, however, the study will move on to a new stage involving the evaluation of further lessons by video conference. This time lessons will be supplemented by pre-packaged lesson materials delivered online and by CD-ROM. The instructional design of these materials and procedures for teaching by video conference will be informed by the findings of the current investigation. Teachers and students will be interviewed and asked to comment on the effectiveness of the teaching and learning materials. Since these teachers and students are already accustomed to working with one another in accord with a set curriculum, both should be able to judge the effectiveness of their teaching and learning by comparing progress with that usually made during conventional lessons. 
While the precise details of improvements in technology are uncertain several trends are clear. Connectivity speed will continue to increase and the geographic availability of high speed connectivity will also improve; computers will become more powerful, hard disk capacities will increase, and computer screens and digital cameras will improve in quality. Correspondingly, video quality will improve and window size will increase. The sending and receiving of cinema length video files and desktop video conferencing with people located at many different sites with little deterioration in the audio or visual quality of the (by then) full screen video will become commonplace in developed countries. Further advances in technology will address the time lag and echo problems which are characteristic of current desktop video conference systems. When this is achieved musicians will be free to participate in real time synchronous performances online with other musicians at different sites around the world.

With the benefit of real time multisite video conferencing it should be easier for teachers to teach larger groups of music students simultaneously. The fact that students are located at different sites (be it next door or on opposite sides of the world) has some unique benefits. For instance, teachers and students would have control over what and whom they choose to see and hear during a shared (multisite) video conference. The benefits of this kind of technical facility have long since been proven through the use of earlier technologies like keyboard labs and in recording studios (Kendall, 1990). The main advantage to the instrumental ensemble teacher is having the ability to isolate the sound of individual students and their instruments during a performance without stopping or interrupting the whole ensemble. Monitoring this way can help teachers to grade the performance of individual players for assessment purposes. This scenario highlights one of the advantages of having each student sitting at their own desktop computer in various remote locations as opposed to teachers trying to teach an entire class located in front of one larger scale room based video conference terminal at the remote site(s). Indeed, Maki (2001, p. 1213) has established that the latter approach is problematic in that "the teacher doesn't always see or hear all the pupils [so] participation during lessons is not always well recognised."

Another advantage of WebCams is that they can be used to provide students with a unique view of their instrument. As noted by Anderson and Ellis (2001), a small WebCam can be inserted into the body of an acoustic instrument such as a guitar, cello, piano or drum. This can help the student to gain a better understanding of how the instrument is constructed and how it produces sound. For instance, one could show students how the soundboard, bridge, strings or skin of the instrument flexes and vibrates as it is played. Hence, the foreseeable benefits of 
desktop video extend beyond its more obvious uses for distance education.

\section{Conclusion}

Whateley and Russell (1997) predicted that university music schools would shift away from full time staffing in favor of using technologies such as video conferencing to provide students with virtual access to satellite session staff (e.g. master musicians whose touring commitments restrict opportunities to visit education institutions in person). To that end professional music teachers around the world will probably adapt their teaching studios, tour buses and the like to make the most of computer based communications technologies. Many are likely to have their own Web site advertising synchronous and asynchronous tuition and fully automated ecommerce facilities, which already exist (Miller, 2001); making it convenient for students to pay lesson fees online.

Teachers will be able to maintain their own databases of FAVs (Frequently Asked for Videos) as well as Frequently Asked Questions (FAQs). Using a password allocated by the teacher's site (probably issued upon receipt of payment by electronic means), students would be able to download prepackaged video lessons as required. Students could refer to these video/lesson packages during their inter-lesson practice. Any difficulties or questions the student may have in relation to a particular technique could be put to the teacher either by email or during a live (synchronous) lesson conducted by video conference. Technical issues like the amount of traffic on the Internet; indeed any packet switched network will always affect the quality of video conferencing. Therefore, some students may prefer to pay more for the option of a video conference lesson via a designated line in order to be sure of getting a high quality/optimum speed video conference link with little or no time delay. This would make it easier for the student to play in real time with the teacher in a 'call and response' solo scenario.

Multimedia lesson packages featuring digital video files may soon be common among published music teaching resources. Nevertheless, the one size fits all nature of generic resources means that little allowance is made for differences in styles of teaching and learning. Consequently, for teachers, the beauty of this 'Do It Yourself' digital video technology is its use to create media that suit their approach to meeting the needs of particular students. Students with a suitable personal computer and a WebCam could be set similar tasks for homework, for example, to record their musical performances. Recording sessions tend to bring out the perfectionist in musicians. Therefore, motivation to practice may increase as students strive to capture their best performance on digital video. Such 
initiatives may take some time to implement, especially for teachers who decide to catalogue most of their repertoire. However, with careful planning, much of the time spent on repetitious aspects of instrumental teaching could be minimised. Then, optimum use could be made of face to face lesson time. Such rationalisation will soon be crucial for teachers who plan to offer synchronous musical instrument tuition online using desktop computer based video conference technology. Clearly, these changes will have a major impact. Taken as a whole these changes may constitute a paradigm shift in music education.

\section{References}

ADS Technologies (2000). Pyro 1394 WebCam. http:/ / www.adstech.com/ (viewed 26 May 2001).

Anderson, A. J. \& Ellis, A. (2001). Moving music education online. Proceedings of the Moving Online II Conference, Jupiters Casino, Gold Coast, Australia, 2-4 Sept 2001.

Bay, M. (1980). Modern Guitar Method. Mel Bay Publications, Missouri.

Brodsky, M. (1995). Blues musicians access to health care. Medical Problems of Performing Artists, 10(1), 18-23.

DCI Music Video Productions (1983). Steve Gadd: Up Close. DCI Music Video Inc, New York.

Eastman Kodak Company (1999). DVC325 Digital Video Camera. http:/ / www.kodak.com/go/dvc325 (viewed 26 May 2001).

Fitzgerald, J. (1999). Popular Music Theory and Musicianship. Hazelmount, Lismore.

Fitzgerald, J. \& Dennis, A. (1999). Business Data Communications and Networking, Sixth Ed, John Wiley \& Sons, New York.

Geake, J. (1987). Some thoughts on flute teaching. The Journal of the Flute Society of NSW, 3(4), 26.

Hays, T. (1998). Mentorship in the training of musicians. Australian Journal of Music Education, 1, 20-25.

Healy, N. (1999). Secrets of the pyramids. internet.au, 52: 80.

Hoffer, C.R. (1989). Teaching Music in the Secondary Schools (4th ed.). Wadsworth, Boston.

Kaufman, D. (Ed.) (1999). Adrian Ballintine interview. internet.au, 50: 43-44.

Kendall, R. (1990). Yamaha's music fundamentals: A programme for the development of music in your school. Australian Music Teacher, 1(2), 107-110.

Logitech (1998). QuickCam VC. http: / / www.logitech.com/pub/ (viewed 26 May 2001).

Maki, J. (2001). Is it possible to teach music in a classroom from distance of 1000 $\mathrm{km}$ ? Learning environment of music education using ISDN video conferencing. 
Proceedings of the Ed-Media 20001 World Conference on Educational Multimedia, Hypermedia and Telecommunications, Tampere, Finland, 2001. AACE, Norfolk, USA, ISBN 1-880094-42-8, pp. 1208-1214.

Madsen. C. K. \& Madsen, C. H. (1969). Experimental Research in Music. New Jersey: Prentice Hall.

Neuman, W. L. (1997). Social Research Methods: Qualitative and Quantitative Approaches. Boston: Allyn \& Bacon.

Newman, L. (1994). Fine tuning your body: Introduction to the Alexander technique. Australian Music Teacher, 3 (5), 366-369.

Persson, R. (1996). Brilliant performers as teachers: A case study of common sense teaching in a conservative setting. International Journal of Music Education, 28, 25-35.

Powell, S. (1984). Teaching the young. The Journal of the Sydney Flute Society, 1(1), 13.

Salvador, R. (1994). What's new in pen computing? Electronic Learning, 13(6), 14.

Scott, A. \& Turner, G. (1994). Progressive Rock Piano. Koala Publications, Hindmarsh, SA.

Shepard, B. (2001). Personal communication via email in August.

St George, J. (1990). Teaching and learning. The Journal of the Flute Society of NSW, 6 (4), 13.

Turner, G. \& White, B. (1979). Progressive Rhythm Guitar. Koala Publications, Burnside, SA.

Van Auken, Z. (1964). Pointer System For Guitar Book 1. Hal Leonard Music. Winona, Minnesota.

Wales, E. (2000). Talking Heads: 'Just for fun' video streaming is becoming big business. The Australian, 28 November.

Whateley, G. and Russell, N. (1997). Rethinking the design and delivery of postgraduate university music courses. Australian Journal of Music Education, 1, 59-68.

Weigert, D. (1997). Effective practice for the bassist and drummer. Jazz Educators Journal, September, 43-49.

Wenig, H. (1994). Letters to the Editor. Australian Music Teacher, 3(5), 324-325.

\section{Alan J. Anderson}

School of Social and Workplace Development, Southern Cross University aanders1@scu.edu.au

Allan Ellis

School of Social and Workplace Development, Southern Cross University aellis@scu.edu.au 